International Journal of Instruction e-ISSN: 1308-1470 • www.e-iji.net

Article submission code: 20200104155946

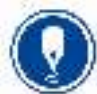

January $2021 \bullet$ Vol.14, No.1

p-ISSN: 1694-609X

pp. 795-812

Received: 04/01/2020

Revision: 01/08/2020
Accepted: 22/08/2020

OnlineFirst:28/11/2020

\title{
Pre-Service Teachers' Prior Learning Experiences of Mathematics and the Influences on Their Beliefs about Mathematics Teaching
}

\section{Wing Yee Lo}

Dr., Woosong University, South Korea, winnielo@wsu.ac.kr

Given the relationship between teacher beliefs and practices, it is critical to understand how pre-service teachers' past school experiences impact on their beliefs about teaching. There is a growing recognition of the influence of preservice teachers' prior mathematical experiences on their beliefs regarding mathematics instruction in the primary school classroom. This qualitative study aimed to investigate Hong Kong primary pre-service teachers' past experiences in learning mathematics and their beliefs about the teaching of mathematics. Nineteen primary pre-service teachers who had selected mathematics as their major in a teacher training program participated in the study. Each participant was required to complete three beliefs tasks in the individual interview in order to recall the teaching of their best mathematics teachers, articulate their memories of learning mathematics, and uncover the kind of primary mathematics teacher they planned to be. The results provided a valuable insight into the effects of pre-service teachers' prior mathematics class incidents on their espoused pedagogical beliefs. While both positive and negative learning experiences of mathematics had a positive impact on interviewees' beliefs about mathematics teaching, most demonstrated their willingness to learn from the past and realised the need to establish better learning environments for their future primary school students.

Keywords: mathematical beliefs, pre-service teachers, primary mathematics, prior learning experiences, teacher education

\section{INTRODUCTION}

Teacher beliefs and classroom practices are closely connected (Chalkiadaki, 2018). Researchers and teacher educators often seek to explore this connection between mathematical beliefs and mathematics teaching practices in order to understand the complexity of beliefs development (Lomas, Grootenboer, \& Attard, 2012). Over the last decade, research on initial teacher preparation in primary mathematics has considered a pre-service teacher's (PST) personal learning experiences as a significant factor influencing his or her mathematical beliefs (e.g., Lloyd \& Howell, 2019; Peker \& Ulu, 2018; Phelps, 2010). It is widely recognised that PSTs' beliefs about how to teach mathematics have a high impact on their instructional practices in the future. Therefore, understanding the relationship between prior learning experiences of mathematics and

Citation: Lo, W. Y. (2021). Pre-Service Teachers' Prior Learning Experiences of Mathematics and the Influences on Their Beliefs about Mathematics Teaching. International Journal of Instruction, 14(1), 795-812. https://doi.org/10.29333/iji.2021.14148a 
beliefs about mathematics teaching can make a significant contribution to the development of teacher education in primary mathematics.

Using an interpretive research paradigm (Ernest, 1998), this study was conducted with a group of PSTs in Hong Kong from a teacher education program preparing primary school teachers. It aimed to explore particular factors influencing Hong Kong PSTs' mathematical beliefs about teaching. Their prior mathematics learning experiences involving the teacher and the classroom incidents were the foci in the investigation. The contributions of the study would be of interest to educational researchers, teacher trainers, and mathematics educators.

The significance of this study is twofold. First, there is a lack of research into PSTs' mathematical beliefs in Hong Kong. Numerous previous and on-going research projects conducted in the local setting focus mainly on the development of strategies for teaching and learning mathematics (Education Bureau, 2019) rather than paying attention to teacher education in mathematics. Internationally, in 2008, the Teacher Education and Development Study in Mathematics (TEDS-M) examined the mathematical knowledge and beliefs of primary and lower secondary PSTs across 17 countries (Tatto et al., 2012). However, Hong Kong did not participate in the TEDS-M study. The present study could address this gap and provide valuable information about Hong Kong PSTs' beliefs regarding mathematics teaching at the primary level.

Second, the study can contribute to an emerging body of research into mathematics teacher education in a Confucian heritage culture context. Different education systems have their unique cultural traditions in mathematics teaching and learning (Jablonka, Wagner, \& Walshaw, 2013). The implemented mathematics curriculum in Hong Kong is primarily influenced by Chinese culture (K. W. Lui \& Leung, 2013). Teacher centeredness along with whole-class instruction is considered to be a key feature of the Confucian heritage classroom in Hong Kong primary schools although constructivist approaches have been highly promoted (Kutnick et al., 2017). This education tradition stands in sharp contrast to innovative pedagogical practices such as inquiry-based learning in mathematics education. It is believed that studying the past mathematical experiences of PSTs in Hong Kong can foster a better understanding of the formation of pedagogical beliefs from a non-Western perspective.

\section{LITERATURE REVIEW}

An extensive search of the literature indicated inconsistent definitions of the term 'beliefs'. In the mathematics education research community, it is commonly accepted that beliefs appear in the form of systems (e.g., Anderson, White, \& Sullivan, 2005; Grootenboer, 2008; Lo \& Anderson, 2010). Teachers' belief systems can be studied from both philosophical and psychological perspectives (Thompson, 1992). In one sense, they are philosophical orientations to teaching mathematics. In another sense, they involve psychological theories impacting teachers' philosophies of mathematics education.

There is a growing body of research concerning mathematical beliefs within the teacher education context. Three kinds of research have dominated the literature about primary 
PSTs' mathematical beliefs. The first has focused on different types of beliefs, including beliefs about the nature of mathematics, as well as about the teaching and learning of mathematics (e.g., Felbrich, Kaiser, \& Schmotz, 2012; Maasepp \& Bobis, 2014); the second has explored the relationships between mathematical beliefs and other domains, such as mathematics teaching anxiety (e.g., Peker \& Ulu, 2018); and the third has measured belief change during the teacher education program (e.g., Leavy \& Hourigan, 2018). The current study was neither a correlation study nor an investigation into belief change. Thus, the review of this paper focuses on the first kind of research, particularly pertaining to a variety of factors affecting beliefs about mathematics teaching which appears in the framework synthesis presented by Lo (2016) showing four types of mathematical beliefs (see Table 1).

Table 1

Synthesis of framework for researching teachers' mathematical beliefs (Lo, 2016)

\begin{tabular}{llll}
\hline $\begin{array}{l}\text { Type of beliefs } \\
\text { Beliefs about } \\
\text { mathematics }\end{array}$ & $\begin{array}{l}\text { Conception of the } \\
\text { nature of mathematics }\end{array}$ & $\begin{array}{l}\text { Beliefs about } \\
\text { mathematics }\end{array}$ & Philipp (2007) \\
\hline $\begin{array}{l}\text { Beliefs about } \\
\text { mathematics teaching }\end{array}$ & $\begin{array}{l}\text { Model of teaching } \\
\text { mathematics }\end{array}$ & $\begin{array}{l}\text { Beliefs about } \\
\text { mathematics } \\
\text { teaching }\end{array}$ & $\begin{array}{l}\text { Beliefs about curriculum } \\
\text { Beliefs about technology }\end{array}$ \\
$\begin{array}{l}\text { Beliefs about } \\
\text { mathematics learning }\end{array}$ & $\begin{array}{l}\text { Model of learning } \\
\text { mathematics }\end{array}$ & $\begin{array}{l}\text { Beliefs about the } \\
\text { self }\end{array}$ & $\begin{array}{l}\text { Beliefs about students' } \\
\text { mathematical thinking } \\
\text { Beliefs about gender }\end{array}$ \\
$\begin{array}{l}\text { Beliefs about the social } \\
\text { context in relation to } \\
\text { mathematics education }\end{array}$ & Principles of education & $\begin{array}{l}\text { Beliefs about the } \\
\text { social context }\end{array}$ & \\
\hline
\end{tabular}

Rokeach (1968) offered a dichotomy for describing all beliefs in his social psychological research. This approach is still very useful because investigations of teacher beliefs frequently expose desirable and undesirable or less desirable beliefs. Different kinds of adjectives and properties have been used to characterise two extreme conceptions of teachers' mathematical beliefs (Österholm, 2011). For instance, A. M. Lui and Bonner (2016) identified primary PSTs' beliefs about mathematics teaching and learning as 'traditional' and 'constructivist'. In turn, Lloyd and Howell's (2019) analysis of PSTs' mathematical beliefs revealed a range from 'strong-traditional' beliefs to 'strong-reform' beliefs with some PSTs holding 'mid-to-weak reform' beliefs. Similarly, in the current study, PSTs' beliefs about mathematics teaching were characterised as 'traditional' or 'reform-oriented' on the basis of Rokeach's (1968) dichotomy.

According to Raymond (1997), there are four factors that go towards the formation of teachers' mathematical beliefs - early family experiences, past school experiences, teacher education programs, and immediate classroom situations. The first three factors seem to account for much of PSTs' mathematics learning experiences whilst the fourth is less pertinent to PSTs due to lack of teaching experience. Primary PSTs' personal school experiences is a major factor influencing their beliefs about mathematics teaching, especially when their experiences of mathematics learning in primary schools were negative (Grootenboer, 2002; Uusimaki \& Nason, 2004). These experiences were 
likely to be a hindrance to the development of their mathematical beliefs. Regardless of personal experiences of learning mathematics, teacher education programs seemed to have an impact on primary PSTs' beliefs about mathematics teaching. A mixed methods longitudinal study conducted by Swars, Smith, Smith, and Hart (2009) revealed that the effects of a teacher education program on primary PSTs' mathematical beliefs varied over time. These findings were supported by other more recent studies (e.g., Jao, 2017; Purnomo, Suryadi, \& Darwis, 2016).

Many researchers used interviews while some used autobiography as a tool for assisting PSTs to reveal their experiences as learners of mathematics (e.g., Stuart \& Thurlow, 2000). In their memories of mathematics lessons, the power of the mathematics teacher was often stressed. For example, Guillaume and Kirtman (2010) carried out an interpretive study with 144 primary PSTs to explore their personal histories with mathematics. Each participant was required to submit an essay about their past experiences which strongly affected them in mathematics. Their results indicated that about half of the participants $(n=73)$ discussed the power of the teacher and stated that the teacher changed their views of mathematics in both positive and negative ways. These participants liked or dreaded the subject because of the comments and behaviours of the mathematics teacher early in primary school and late in college. Apart from teachers in schools, teacher educators may also have an impact on primary PSTs' beliefs about mathematics teaching (Shilling-Traina \& Stylianides, 2013). For the current study, primary PSTs' prior mathematics learning experiences related to the teacher and the mathematics classroom (including the teacher education program) were investigated.

There were two research questions guiding the study:

1. What were the past mathematical experiences of PSTs in Hong Kong?

2. How do PSTs' prior learning experiences of mathematics influence their beliefs about mathematics teaching?

\section{METHOD}

Qualitative research methods were employed in the design of this study. To investigate the past mathematical experiences of PSTs in Hong Kong and to reveal the characteristics of their beliefs about mathematics teaching, a cross-sectional design was adopted in order to produce a snapshot of the population at a specific point in time.

\section{Participants}

Since some earlier studies have suggested that graduating PSTs demonstrate more desirable beliefs than beginning PSTs (e.g., Swars et al., 2009), this study considered PSTs' beliefs about mathematics teaching throughout the 4-year undergraduate teacher education program in Hong Kong. Across four year groups of the program, all primary PSTs who had selected mathematics as their major were invited to participate in the study. A total of 19 PSTs agreed to be interviewed. Of these 19 interviewees, four each from Year 1 to Year 3 and seven from Year 4, five were male and 14 were female. A pseudonym was created for each interviewee to assist with the presentation of results. 


\section{Interview Protocol}

The individual interviews were semi-structured. Interviewees were required to complete the three beliefs tasks in the interview protocol (see Table 2). These tasks were adapted from Marland's (2007) interview protocol that helped PSTs articulate their pre-existing theories of teaching.

Table 2

Interview questions in the three beliefs tasks (adapted from Marland, 2007, pp. 45-48)

\begin{tabular}{ll}
\hline Beliefs task & Interview question \\
\hline Task One & Recalling the teaching of a good mathematics teacher who taught you \\
& 1. Who was your best mathematics teacher? \\
& 2. What are the reasons for you to identify this teacher to be the best one you \\
& ever had? \\
3. Why do you consider those characteristics and behaviours so important?
\end{tabular}

Tasks One and Two addressed PSTs' prior learning experiences of mathematics. These two tasks required the interviewees to recall and articulate their memories of learning mathematics. Task Three aimed to gain insight into PSTs' emerging identities as primary mathematics teachers. The follow-up questions involved in the third task were intended to probe the relationship between prior learning experiences of mathematics and beliefs about mathematics teaching.

\section{Data Collection and Analysis}

There was a set of participant information sheets and consent forms for this study. The Chinese version of these documents was given to the 19 interviewees. These documents were translated through the standard translation and back-translation procedure. Each interview took about 30 minutes and was audio-recorded. Cantonese which is a mainstream dialect of Hong Kong people was the verbal language used in the interviews. Quotations from interviewees cited in this paper were translated into English. A thematic approach was adopted to analyse the interview data. With an assistance of the software NVivo, a data-driven strategy for generating categories was used in the analysis of interview transcripts. 


\section{FINDINGS AND DISCUSSION}

\section{The Best Mathematics Teachers}

The best mathematics teachers nominated by the primary PTSs emerged at various stages of their education. A timeline shown in Figure 2 represents the Hong Kong education system experienced by the majority of participants. Among the 19 interviewees, seven had encountered their best mathematics teachers in primary schools, 10 in secondary schools, and two in the undergraduate teacher education program. This distribution is represented as a scattergram in Figure 2.

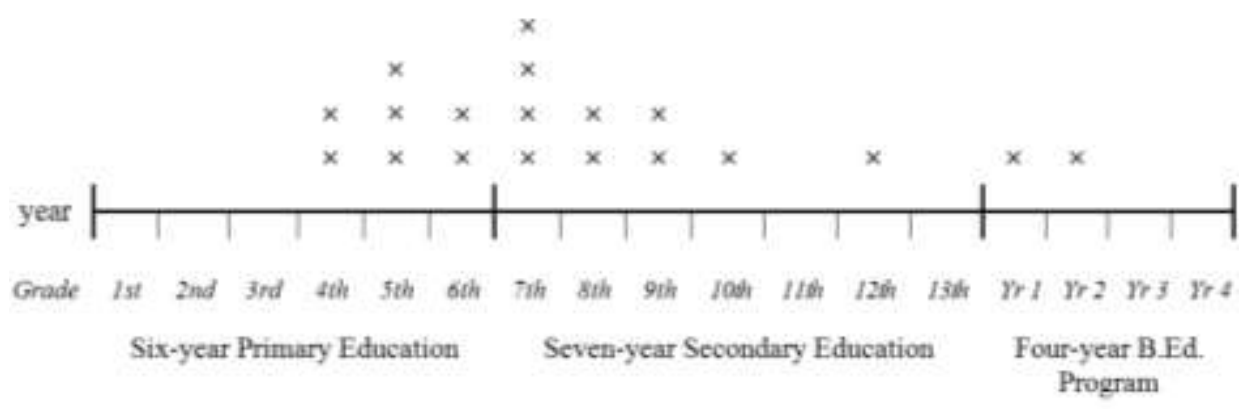

Figure 2

Timeline of Hong Kong education system with scattergram indicating the grade level for interviewees' favourite mathematics teachers.

The scattergram in Figure 2 indicates a clustering of favourite mathematics teachers at the later stages of primary education and the early stages of secondary education. Nine sub-categories emerged from an analysis of their reasons for this choice. The responses from seven interviewees were classified into more than one sub-category. These subcategories were identified as belonging to two categories. The categories were labelled as 'instructional practices' and 'personal qualities' (see Table 3).

Table 3

Categories and sub-categories for interviewees' identification of their best mathematics teacher (numbers in brackets indicate interviewees whose responses were included in this sub-category)

\begin{tabular}{ll}
\hline Category & Sub-category \\
\hline Category I - Instructional practices & Catering for the needs of students $(\mathrm{n}=5)$ \\
& Motivating students to learn $(\mathrm{n}=5)$ \\
& Improving the academic performance of students $(\mathrm{n}=3)$ \\
& Teaching and presentation skills of teachers $(\mathrm{n}=3)$ \\
& Developing the thinking skills of students $(\mathrm{n}=1)$ \\
\hline Category II - Personal qualities & Conscientiousness $(\mathrm{n}=3)$ \\
& Patience $(\mathrm{n}=3)$ \\
& Toughness $(\mathrm{n}=3)$ \\
& Enthusiasm $(\mathrm{n}=2)$ \\
\hline
\end{tabular}

International Journal of Instruction, January $2021 \bullet$ Vol.14, No.1 
Seventeen interviewees referred to the impact teachers had made on their mathematics learning including teachers' practices (category I) such as catering for their needs, motivating them to learn, improving their academic performance, developing their thinking skills, and teachers' presentation skills. Each of these sub-categories is discussed here with sample comments.

Mathematics teachers who catered for the different needs of students were greatly appreciated by the PTSs. Five interviewees' responses were grouped into the first subcategory, catering for the needs of students, with examples of responses provided by Monica and Irene. Monica had moved to Hong Kong from Mainland China in the middle of the academic year in Grade Four. According to her responses, the content of the primary mathematics curriculum in Mainland China was considered to be more difficult than in Hong Kong so that her mathematics performance was better than other students in the class. Monica nominated her primary mathematics teacher to be the best because this teacher addressed her mathematical ability and enhanced her confidence in learning:

Ms Lau gave additional mathematics exercises for me to do, and also provided mathematics training to prepare me to represent the school in mathematics competitions. I was so grateful to her. (Monica, a Year 4 PST)

In contrast, Irene nominated her secondary mathematics teacher to be the best because this teacher assisted her to learn mathematics in English. The instructional language used in Hong Kong mainstream primary schools is Chinese. Similar to many Hong Kong students, Irene had to learn mathematics in English when she was studying in secondary school. It was a big change for her but her seventh-grade mathematics teacher helped her to overcome the challenge.

The second sub-category, motivating students to learn, was another reason for five PSTs identifying their best mathematics teachers. Tina and Angel agreed with the power of encouragement for primary school students. Tina was interested in mathematics because of an award scheme implemented by her primary mathematics teacher. She was awarded a bookmark as a gift when she correctly solved a mathematics problem. A similar award scheme also motivated Angel to put more effort into solving mathematics problems when she was in Grade Five.

In addition to award schemes, oral complements and written comments were other strategies interviewees recalled teachers using to increase their motivation to learn. For example, Carrie was motivated when she heard her teacher saying "I am happy to see your progress". Some encouraging words written by Yvonne's teacher, such as "failure is the mother of success" highly motivated her. It should be noted that the sub-category of motivation only appeared in the responses of interviewees identifying their best mathematics teachers from primary schools. For the PTSs who nominated their secondary mathematics teachers, none of their responses were classified into this subcategory. They seemed to have thought that it was important for primary school teachers to arouse their interest in mathematics. 
The third sub-category which emerged from the interview data was improving the academic performance of students and was nominated by three PSTs. For instance, Josie nominated her eighth-grade mathematics teacher because she had made significant progress under the teacher's instruction. Helen stated that her mathematics performance was improved because her ninth-grade mathematics teacher provided opportunities for extensive practice. Both Josie and Helen emphasised the importance of achieving higher academic results in secondary school. They regarded students' mathematics performance as an indicator for determining the efficacy of a mathematics teacher.

Three PSTs emphasised that it was important for a mathematics teacher to communicate mathematical knowledge in a clear way so as not to confuse students. Their responses were identified as belonging to the fourth sub-category, teaching and presentation skills of teachers. Kerry and Susan appreciated the teacher who could "speak slowly" and "explain clearly" so that they could easily follow the teacher's instructions in class.

Lydia was the only interviewee whose responses were placed under the fifth subcategory - developing students' thinking skills. Lydia claimed that a tutor who was teaching mathematics in the teacher education program was the best one she had ever encountered. She described this tutor as "knowledgeable and sensible" so that he facilitated her mathematical thinking. Lydia determined the efficacy of a mathematics teacher from a different perspective. She admired her tutor because he showed her how to be a professional mathematics teacher. From her point of view, it was important for a teacher to develop students' thinking skills in order to broaden their horizons:

Academic achievement is not the only outcome of education. I think a good teacher should be able to facilitate students' thinking. Such as the tutor I have mentioned before, he can inspire me to think about something new in order to widen our horizons. (Lydia, a Year 3 PST)

The second category of responses to emerge from an analysis of the interview data was labelled 'personal qualities' and included four sub-categories: conscientiousness, patience, toughness, and enthusiasm. An example of a response for each sub-category is provided in Table 4. 
Table 4

Examples for the second category of interviewees' identification of the best mathematics teacher (numbers in brackets indicate interviewees whose responses were included in this sub-category)

\begin{tabular}{ll}
\hline Sub-category & Selected response of interviewees \\
\hline Category II - Personal qualities & \\
\hline Conscientiousness (n=3) & $\begin{array}{l}\text { In my primary school, my mathematics was not very good. } \\
\text { This fourth-grade teacher was willing to spend her time after } \\
\text { school to guide me through the homework. (Eva, a Year 1 } \\
\text { PST) }\end{array}$ \\
\hline Patience (n=3) & The teacher was so patient. He was happy to answer our \\
& questions. He did not mind repeating his responses if we \\
required. (Oscar, a Year 2 PST)
\end{tabular}

Seven out of 19 interviewees nominated their best mathematics teachers according to teachers' personal qualities. Some PSTs considered conscientiousness and toughness to be desirable qualities of a good mathematics teacher. Nicole regarded her seventh-grade mathematics teacher to be the best because her teacher possessed these two personal qualities.

The findings of primary PSTs' best mathematics teachers provided considerable insights into their mathematical beliefs. Two categories including instructional practices (category I) and personal qualities (category II) particularly referred to their beliefs about mathematics teaching. The majority of the responses were classified as category I suggesting most of the PSTs nominated their best mathematics teachers according to their teaching practices.

Although these findings affirmed the orientation of primary PSTs' reform-oriented beliefs about mathematics teaching, the more traditional mathematical beliefs about mathematics, mathematics teaching, and mathematics learning were reflected in some of their responses. Examples of responses referring to the more traditional mathematical beliefs of focusing on correct answers and examination preparation included:

Mathematics should be taught as a right and wrong subject. Getting the right answer is paramount. (Rachel, a Year 4 PST)

Mathematics teachers should provide lots of exercises for students to do in order to prepare them for examinations. (Helen, a Year 1 PST) 
Learning mathematics - practice makes perfect. (Nicole, a Year 4 PST)

It is important for Hong Kong students to achieve good examination results, including mathematics. (Gary, a Year 4 PST)

Overall, the analysis found that for most of the PSTs their favourite mathematics teachers created a positive influence on their mathematics learning. It was evident that their best primary school teachers increased their motivation to learn mathematics while their best secondary school teachers improved their mathematics performance. Furthermore, the personal qualities of a good mathematics teacher considered by the PSTs varied. Apart from the teacher personality traits in general, such as conscientiousness and patience, a small proportion of PSTs also appreciated a tough mathematics teacher who was strict, reflecting that some PSTs believed the traditional Chinese proverb that "an outstanding apprentice/student is produced by a strict teacher" (Hui, 2005, p. 28). These results are consistent with earlier research conducted by Shao, Fan, Huang, Ding, and Li (2013) reporting a strong impact of the Confucian view of teaching on mathematics education in East Asian societies.

\section{Memorable Class Incidents}

The second beliefs task from the interview required the primary PSTs to recall memorable positive and negative incidents from their mathematics classes. Of the 19 interviewees, 15 provided one positive classroom incident while 14 described one negative classroom incident. From an analysis of these responses, five sub-categories emerged - these were then grouped into the two categories of 'positive learning experiences' and 'negative learning experiences' (see Table 5).

Table 5

Categories and sub-categories for interviewees' past mathematics learning experiences (numbers in brackets indicate interviewees whose responses were included in this subcategory)

\begin{tabular}{ll}
\hline Category & Sub-category \\
\hline Category I - Positive learning experiences & Innovative teaching methods $(\mathrm{n}=13)$ \\
& Traditional teaching methods $(\mathrm{n}=2)$ \\
\hline Category II - Negative learning experiences & Punishment $(\mathrm{n}=6)$ \\
& Teachers' discouraging comments $(\mathrm{n}=4)$ \\
& Mathematics tests and examinations $(\mathrm{n}=4)$ \\
\hline
\end{tabular}

The first category 'positive learning experiences' involved two sub-categories: innovative teaching methods and traditional teaching methods. It was common that the positive classroom incidents were initiated by the teaching methods adopted in the mathematics classes. Where the PSTs mentioned group discussions, role-playing games, problem solving activities, this was categorised in the first sub-category. Similarly mention of examinations, reciting formulas, doing classwork and homework were classified into the second sub-category.

Thirteen PSTs' responses were categorised as belonging to the first sub-category innovative teaching methods. For example, Yvonne recalled how she understood a 
mathematics problem through "role-play". Gary was happy that his secondary teacher used "a game instead of a test" to assess his mathematics performance.

Only two Year 1 PSTs' responses were classified as belonging to the second subcategory - traditional teaching methods. Eva and Carrie's responses referred to their positive experiences of failure in examinations and recitation respectively:

My mathematics teacher did not blame me for my poor examination results. (Eva, a Year 1 PST)

When I did not correctly recite the mathematical formula in the class, the teacher was happy to give me one more day to do it. (Carrie, a Year PST)

In response to the question concerning the negative classroom incidents relevant to mathematics learning, a variety of descriptions from both discouragement and punishment were provided. Three sub-categories were generated under the second category of 'negative learning experiences'. They were labelled punishment, teachers' discouraging comments, and mathematics tests and examinations accordingly.

Different kinds of punishment caused a fear of mathematics. Six PSTs mentioned castigation and physical punishment in the mathematics classes. For instance, Eva experienced verbal abuse in her 10th-grade mathematics class. She got blamed for her misunderstanding of a mathematics problem. Fred felt physically ill when one teacher abused a student since he thought "it wasted time and also damaged the learning atmosphere".

Although corporal punishment is not allowed in the Hong Kong education system, minor physical punishment such as standing up for a long time is a common way to punish students. Susan experienced this kind of punishment in a secondary mathematics class. Because she did not know how to solve a particular mathematical problem, her teacher asked her to stand in front of the blackboard for a period of time as a punishment.

Besides punishment, discouraging comments also led to PSTs' unpleasant memories of mathematics. Four PSTs were discouraged by what mathematics teachers said and their responses were identified as belonging to the first sub-category - teachers' discouraging comments. They recounted their negative experiences and remembered every word, such as "You are so silly" (Gary, a Year 4 PST) and "Whatever you do, you can't pass the public examination" (Rachel, a Year 4 PST). Tina mentioned that her classmate was discouraged by an 11th-grade mathematics teacher. Although it happened to another student, Tina also had negative feelings when she heard the discouraging comments.

Moreover, four PSTs described their negative feelings about getting unsatisfactory test results from mathematics teachers. These responses were identified as belonging to the third sub-category - mathematics tests and examinations. Angel was frustrated because she was not satisfied with her test result. Yvonne recounted her experience of boredom when the mathematics class focussed on reviewing past examination papers. 
In short, an analysis of PSTs' past mathematics learning experiences revealed some significant findings. Many PSTs reported a high degree of acceptance and appreciation of innovative teaching methods that are proposed in the primary mathematics curriculum (Curriculum Development Council, 2017) while they learnt mathematics in school by means of both 'new' and 'old' teaching methods (see Table 5). However, the results also showed that some of the PSTs preferred more traditional teaching approaches such as drill and practice. Regarding PSTs' negative experiences, it was common that they had experienced discouragement, fear and boredom in mathematics learning at their primary and secondary schools. These results are of concern and resonate with previous studies suggesting a need to create a genuine inquiry-based learning environment in Hong Kong classrooms (e.g., Kutnick et al., 2017; Yeung, 2009).

\section{Identities as Primary Mathematics Teachers}

The third beliefs task sought PSTs' ideas on their identities as professional primary mathematics teachers and involved the core question, 'Could you describe in detail what kind of primary mathematics teacher you want to be?' Four sub-categories emerged from an analysis of the interview transcripts: student-centred descriptions, learningfocused descriptions, teacher-centred descriptions, and school-based descriptions. The responses from seven interviewees were classified into more than one sub-category. The sub-categories were further classified into two categories of 'traditional beliefs about mathematics teaching' and 'reform-oriented beliefs about mathematics teaching'. A sample response for each sub-category is provided in Table 6.

Table 6

Categories, sub-categories, and examples for interviewees' beliefs about mathematics teaching (numbers in brackets indicate interviewees whose responses were included in this sub-category)

\begin{tabular}{|c|c|}
\hline Sub-category & Selected response of interviewees \\
\hline \multicolumn{2}{|c|}{ Category I - Reform-oriented beliefs about mathematics teaching } \\
\hline $\begin{array}{l}\text { Student-centred } \\
\text { descriptions }(\mathrm{n}=14)\end{array}$ & $\begin{array}{l}\text { I will create a positive learning environment for my future students. } \\
\text { (Monica, a Year } 4 \text { PST) }\end{array}$ \\
\hline $\begin{array}{l}\text { Learning-focused } \\
\text { descriptions }(n=2)\end{array}$ & $\begin{array}{l}\text { I want to develop students' higher-order thinking skills, especially their } \\
\text { problem solving skills. (Gary, a Year } 4 \text { PST) }\end{array}$ \\
\hline \multicolumn{2}{|c|}{ Category II - Traditional beliefs about mathematics teaching } \\
\hline $\begin{array}{l}\text { Teacher-centred } \\
\text { descriptions }(n=7)\end{array}$ & $\begin{array}{l}\text { I would like to be a tough teacher. Students have to follow my every } \\
\text { instruction in the class. (Nicole, a Year } 4 \text { PST) }\end{array}$ \\
\hline $\begin{array}{l}\text { School-based } \\
\text { descriptions }(n=2)\end{array}$ & $\begin{array}{l}\text { I want to be a teacher meeting school expectations. (Angel, a Year } 1 \\
\text { PST) }\end{array}$ \\
\hline
\end{tabular}

Sixteen of the 19 PSTs' responses fell under the first category 'reform-oriented beliefs about mathematics teaching'. Responses relevant to students' mathematics learning experiences or students' feelings about mathematics were identified as belonging to the first sub-category - student-centred descriptions. David said he would provide opportunities for students to explore mathematical knowledge. Carrie said she would not let her students fear mathematics. 
When the PSTs stated what kind of mathematics teacher they planned to be, Monica and Gary aimed to develop students' particular skills through mathematics learning. Monica wanted her students to apply the mathematical knowledge in their daily lives. Gary wanted to develop students' higher order thinking skills, especially their problem solving skills. Their responses were classified as belonging to the second sub-category learning-focused descriptions.

Although 16 PSTs' beliefs about mathematics teaching tended to reflect reform-oriented beliefs, two sub-categories emerged from the data that were identified as belonging to the second category 'traditional beliefs about mathematics teaching'. Responses focused on what teachers should do and should not do were grouped into the first sub-category teacher-centred descriptions. For instance, Fred wished his students would "worship him as their idol". Paul hoped to "control the class with his classroom management techniques". Two other PSTs planned to be primary mathematics teachers who followed the school policy and requirements. Their responses were identified as belonging to the second sub-category - school-based descriptions.

The interview data indicated that some PSTs possessed a mixture of traditional and reform-oriented beliefs about mathematics teaching with six PSTs' responses being identified under both categories. The following statement provided by Kerry was a typical example:

I want to equip myself with enough classroom management skills. Students have to follow my every instruction to learn mathematics in the class. ... I will try to understand different learning styles among students. (Kerry, a Year 3 PST)

Kerry demonstrated mixed beliefs about mathematics teaching. Her descriptions were classified as being both teacher-centred and student-centred. For instance, she wanted to be a teacher catering for individual differences, which reflects a student-centred approach, but she also wanted to be an authority in the class in order to control her students' mathematics learning, which is associated with more teacher-centred approaches.

The interview data also revealed that PSTs' negative learning experiences could influence their beliefs about mathematics teaching in a positive way. Seven out of 19 interviewees referred to their negative prior school experiences of mathematics in reply to the third beliefs task, 'Why do you want to be this kind of primary mathematics teacher?' None of the interviewees referred to positive learning experiences when they answered this question. Helen wanted to be a teacher who could use daily life examples to teach students abstract concepts because of her unpleasant experiences in learning fractions. Paul wanted to create an interesting mathematics class for his future students because he experienced boredom in mathematics learning. Gary wanted to develop his future students' higher-order thinking skills because he thought that his own school teachers did not do this for him. Therefore, it seems that PSTs' negative prior school experiences can potentially have a positive impact on the kind of primary mathematics teacher they wanted to be. These results are compatible with those found in Siswono, Kohar, Hartono, Kurniasari, and Karim's (2019) study, showing that teachers' beliefs 
about mathematics teaching and learning were mainly influenced by their recognition of the importance of mathematics curriculum reform, but not by their past learning experiences of mathematics.

\section{CONCLUSION}

The primary PSTs in this study critically reflected on their own mathematics learning during the interviews to reveal how they had learnt mathematics at school. They judged their mathematics teachers according to their instructional practices and personal qualities. The positive learning experiences included not only innovative teaching methods but also traditional teaching methods. Their negative learning experiences included teachers' discouraging comments, punishment, and focus on examinations.

Moreover, the articulation of a professional identity for each of the PSTs provided further information regarding the complexity of their beliefs about mathematics teaching. Their responses were mainly associated with reform-oriented beliefs but some tended to be traditional, reflecting a 'teacher as authority' perspective. Thus, there appears to be some inconsistency or a potential conflict between PSTs' mathematical beliefs and the philosophy of the revised student-centred curriculum (Curriculum Development Council, 2017). Parts of the interview results also provided an insight into how prior mathematics class incidents influenced their mathematical beliefs. Both PSTs' positive and negative school experiences of mathematics could have a positive influence on their beliefs about mathematics teaching. The PSTs demonstrated their willingness to learn from the past and realised the need to establish more positive learning environments for their future students.

These results imply that some PSTs appear to demonstrate more traditional beliefs about mathematics teaching which may be a consequence of greater exposure to actual inschool practicum experiences. It is challenging for teacher educators to change PSTs' conventional mathematical beliefs since PSTs have their own past mathematics learning experiences. Consideration of teaching placements creating an opportunity for reflections and further provoking PSTs' pedagogical beliefs, it is advised that teacher educators should provide an open and supportive mentoring environment during practicum in order to reconstruct PSTs' beliefs about mathematics teaching.

This qualitative study provided rich and detailed descriptions of participants' mathematical beliefs. Nonetheless, it may not be possible to generalise the results from the study to other primary PSTs because only a small amount of participants volunteered to be interviewed. Advice for future research would be to involve a larger number of PSTs and incorporate a mixed methods approach, and hence to increase trustworthiness of the findings and overcome the weaknesses of qualitative approach.

\section{ACKNOWLEDGE}

This research received funding from Woosong University Academic Research Funding 2020. 


\section{REFERENCES}

Anderson, J., White, P., \& Sullivan, P. (2005). Using a schematic model to represent influences on, and relationships between, teachers' problem-solving beliefs and practices. Mathematics Education Research Journal, 17(2), 9-38.

Chalkiadaki, A. (2018). A systematic literature review of 21 st century skills and competencies in primary education. International Journal of Instruction, 11(3), 1-16. doi: $10.12973 / \mathrm{iji} .2018 .1131 \mathrm{a}$

Curriculum Development Council. (2017). Supplement to mathematics education key learning area curriculum guide: Learning content of primary mathematics. Hong Kong: Education Department.

Education Bureau. (2019). Mathematics education - Collaborative research and development ("seed") projects / "seed" projects. Retrieved May 27 2019, from https://www.edb.gov.hk/en/curriculum-development/kla/ma/seed.html

Ernest, P. (1989). The knowledge, beliefs and attitudes of the mathematics teacher: A model. Journal of Education for Teaching, 15(1), 13-33.

Ernest, P. (1998). The epistemological basis of qualitative research in mathematics education: A postmodern perspective. Journal for Research in Mathematics Education, 9, 22-39.

Felbrich, A., Kaiser, G., \& Schmotz, C. (2012). The cultural dimension of beliefs: An investigation of future primary teachers' epistemological beliefs concerning the nature of mathematics in 15 countries. ZDM Mathematics Education, 44, 355-366.

Grootenboer, P. (2002). Affective development in mathematics: A case study of two preservice primary school teachers. In B. Barton, K. C. Irwin, M. Pfannkuch \& M. O. J. Thomas (Eds.), Mathematics Education in the South Pacific: Proceedings of the 25th Annual Conference of the Mathematics Education Researcher Group of Australasia (pp. 318-325). Sydney: MERGA.

Grootenboer, P. (2008). Mathematical belief change in preservice primary teachers. Journal of Mathematics Teacher Education, 11(6), 479-497.

Guillaume, A. M., \& Kirtman, L. (2010). Mathematics stories: Preservice teachers' images and experiences as learners of mathematics. Issues in Teacher Education, 19(1), 121-143.

Hui, L. (2005). Chinese cultural schema of Education: Implications for communication between Chinese students and Australian educators. Issues in Educational Research, 15(1), 17-36.

Jablonka, E., Wagner, D., \& Walshaw, M. (2013). Theories for studying social, political and cultural dimensions of mathematics education. In M. A. Clements, A. Bishop, C. Keitel-Kreidt, J. Kilpatrick \& F. K. S. Leung (Eds.), Third international handbook of mathematics education (pp. 41-67). New York: Springer. 
Jao, L. (2017). Shifting pre-service teachers' beliefs about mathematics teaching: The contextual situation of a mathematics methods course. International Journal of Science and Mathematics Education, 15(5), 895-914. doi: 10.1007/s10763-016-9719-9

Kutnick, P., Fung, D. C. L., Mok, I. A. C., Leung, F. K. S., Li, J. C. H., Lee, B. P.-Y., \& Lai, V. K. W. (2017). Implementing effective group work for mathematical achievement in primary school classrooms in Hong Kong. International Journal of Science and Mathematics Education, 15(5), 957-978. doi: 10.1007/s10763-016-9729-7

Leavy, A., \& Hourigan, M. (2018). The beliefs of "tomorrow's teachers" about mathematics: Precipitating change in beliefs as a result of participation in an initial teacher education programme. International Journal of Mathematical Education in Science and Technology, 49(5), 759-777. doi: 10.1080/0020739X.2017.1418916

Lloyd, M. E. R., \& Howell, M. (2019). Positioning pre-service teacher beliefs along the traditional-reform continuum: An examination of normative beliefs and discursive claims. The Mathematics Enthusiast, 16(1-3), 155-210.

Lo, W. Y. (2016). Rethinking teacher preparation: Towards a conceptual framework for the study of mathematical knowledge and beliefs. Daejeon, South Korea: Woosong University Press.

Lo, W. Y., \& Anderson, J. (2010). Beyond the curriculum: The mathematical beliefs of pre-service primary teachers in Hong Kong. In L. Sparrow, B. Kissane \& C. Hurst (Eds.), Shaping the Future of Mathematics Education: Proceedings of the 33rd Annual Conference of the Mathematics Education Research Group of Australasia (pp. 657664). Fremantle, WA: MERGA.

Lomas, G., Grootenboer, P., \& Attard, C. (2012). The affective domain and mathematics education. In B. Perry, T. Lowrie, T. Logan, A. MacDonald \& J. Greenlees (Eds.), Research in Mathematics Education in Australasia 2008-2011 (pp. 23-37). Rotterdam: Sense Publishers.

Lui, A. M., \& Bonner, S. M. (2016). Preservice and inservice teachers' knowledge, beliefs, and instructional planning in primary school mathematics. Teaching and Teacher Education, 56, 1-13.

Lui, K. W., \& Leung, F. K. S. (2013). Curriculum traditions in Berlin and Hong Kong: A comparative case study of the implemented mathematics curriculum. ZDM Mathematics Education, 45, 35-46.

Maasepp, B., \& Bobis, J. (2014). Prospective primary teachers' beliefs about mathematics. Mathematics Teacher Education and Development, 16(2), 89-107.

Marland, P. (2007). Learning to teach: A primer for pre-service teachers. Frenchs Forest: Pearson Education Australia.

McLeod, D. B. (1992). Research on affect in mathematics education: A reconceptualization. In D. A. Grouws (Ed.), Handbook of research on mathematics 
teaching and learning: A project of the national council of teachers of mathematics (pp. 575-596). New York: Macmillan.

Österholm, M. (2011). Characterizing mathematics education research discourse on belief. In K. Kislenko (Ed.), Current State of Research on Mathematical Beliefs XVI: Proceedings of the MAVI-16 Conference (pp. 200-217). Tallinn, Estonia: Institute of Mathematics and Natural Sciences,Tallinn University.

Peker, M., \& Ulu, M. (2018). The effect of pre-service mathematics teachers' beliefs about mathematics teaching-learning on their Mathematics teaching anxiety. International Journal of Instruction, 11(3), 249-264. doi: 10.12973/iji.2018.1138a

Phelps, C. M. (2010). Factors that pre-service elementary teachers perceive as affecting their motivational profiles in mathematics. Educational Studies in Mathematics, 75(3), 293-309.

Philipp, R. A. (2007). Mathematics teachers' beliefs and affect. In F. K. Lester (Ed.), Second handbook of research on mathematics teaching and learning (pp. 257-315). Charlotte, NC: Information Age Publishing.

Purnomo, Y. W., Suryadi, D., \& Darwis, S. (2016). Examining pre-service elementary school teacher beliefs and instructional practices in mathematics class. International Electronic Journal of Elementary Education, 8(4), 629-642.

Raymond, A. (1997). Inconsistency between a beginning elementary school teacher's mathematics beliefs and teaching practice. Journal for Research in Mathematics Education, 28(5), 550-576.

Rokeach, M. (1968). Beliefs, attitudes and values: A theory of organization and change. San Francisco: Jossey-Bass Inc.

Shao, G., Fan, Y., Huang, R., Ding, E., \& Li, Y. (2013). Mathematics classroom instruction in China viewed from a historical perspective. In Y. Li \& R. Huang (Eds.), How Chinese teach mathematics and improve teaching (pp. 11-28). New York: Routledge.

Shilling-Traina, L. N., \& Stylianides, G. J. (2013). Impacting prospective teachers' beliefs about mathematics. ZDM Mathematics Education, 45, 393-407.

Siswono, T. Y. E., Kohar, A. W., Hartono, S., Kurniasari, A. H. R. I., \& Karim, K. (2019). Examining teacher mathematics-related beliefs and problem-solving knowledge for teaching: Evidence from Indonesian

primary and secondary teachers. International Electronic Journal of Elementary Education, 11(5), 493-506. doi: 10.26822/iejee.2019553346

Stuart, C., \& Thurlow, D. (2000). Making it to their own: Preservice teachers' experiences, beliefs, and classroom practices. Journal of Teacher Education, 51(2), 113-124. 
Swars, S. L., Smith, S. Z., Smith, M. E., \& Hart, L. C. (2009). A longitudinal study of effects of a developmental teacher preparation program on elementary prospective teachers' mathematics beliefs. Journal of Mathematics Teacher Education, 12(1), 47-66.

Tatto, M. T., Schwille, J., Senk, S., Ingvarson, L., Rowley, G., Peck, R., . . . Reckase, M. (2012). Policy, practice, and readiness to teach primary and secondary mathematics in 17 countries: Findings from the IEA Teacher Education and Development Study in Mathematics (TEDS-M). The Netherlands, Amsterdam: International Association for the Evaluation of Educational Achievement (IEA).

Thompson, A. (1992). Teachers' beliefs and conceptions: A synthesis of the research. In D. Grouws (Ed.), Handbook of research in mathematics teaching and learning (pp. 390-419). New York: Macmillan.

Uusimaki, L., \& Nason, R. (2004). Causes underlying pre-service teachers' negative beliefs and anxieties about mathematics. In M. J. Høines \& A. B. Fuglestad (Eds.), Proceedings of the 28th Conference of the International Group for the Psychology of Mathematics Education (Vol. 4, pp. 369-376). Bergen: PME.

Yeung, S. Y. S. (2009). Is student-centered pedagogy impossible in Hong Kong? The case of inquiry in classrooms. Asia Pacific Education Review, 10(3), 377-386. 